\title{
Evidence of Poor Environments in Shared Outdoor Spaces of Residential Complexes in Iran
}

\author{
Reza Ramyar ${ }^{1 *}$, Zahra Hayati ${ }^{2}$, Saeed Saeedi ${ }^{3}$, Mohammad Mahdi Taj ${ }^{4}$ \\ ${ }^{1}$ State University of New York, College of Environmental Science and Forestry \\ ${ }^{2}$ School of Architecture and Urban Planning, Tehran University of Art \\ ${ }^{3}$ School of Architecture and Urban Planning, Shahid Beheshti University \\ ${ }^{4}$ Department of Social Science, Shahid Beheshti University
}

Received: 7 December 2017

Accepted: 28 January 2018

\begin{abstract}
Nearly half a century has passed since the emergence of modernity's aspects in the way of building houses in Iran. With long time passing from the life of this experience, the pattern of residential complex development did not change much compared to the beginning and its results can be seen in the design quality and satisfaction of residents from space. Clearly the expense of land as well as adequate knowledge and lack of awareness are the main reasons for the poor quality of design. Outdoor space in this type of development was under fundamental changes so that the type of ownership, access, and size of this space gained a different nature that has not been known clearly, and poor environmental quality is its main consequence. The scope of this paper is to recognize divergences - resulting in environment quality - from residential complex construction in Iran. For this goal, at the beginning some main concerns related to environmental quality are explained, and then related issues are examined. Finally, the quality of open spaces in residential complexes in Tehran, the capital of Iran, is discussed. In order to succeed in this objective, data have been derived from 235 cases in four residential complexes by means of a questionnaire that includes 54 questions, and results of this survey were evaluated by Chronbach's Alpha and the percentage values were calculated by frequencies of the answers. It is concluded that the residents are not adequately satisfied by the quality of open environment provided by their housing units.
\end{abstract}

Keywords: environment quality, shared open spaces, residential complexes, Iran

\section{Introduction}

All through the history of researching housing and neighbourhood environments there have been attempts to describe neighbourhoods with summary measures of their overall quality. Satisfaction and attachment are two major summary factors that have an important influence on the overall quality of residents' lives. While satisfaction has been studied frequently in neighbourhood research [1-3], several other indicators have also been used to measure perceived neighbourhood quality. People's attachment to and preference for residential outdoor space has been well documented by some authors [4-6]. Van Herzele and de Vries [7] insisted that other factors of the built 
environment influence community satisfaction as well, such as housing quality, neighbourhood quality, and ease of access to nature. Buonfino and Hilder [8] support this evidence, claiming that larger residences, access to local parks, and block design using cul-de-sacs lead to more satisfaction. According to Buys and Miller [9], objective factors such as the size and type of community and the quality of the physical neighbourhood are particularly important in developing a sense of satisfaction and feeling toward the community. Turkey Oktay et al. [10] have been shown that satisfaction with open space does not necessarily relate to place attachment, and despite the realization of lacking certain social-spatial qualities in the neighbourhood, people may feel attached to the place because of certain features. However, there is a positive relationship between satisfaction and feelings of neighbourhood as home. Achieving a sense of comfort in an environment is one of the niceties of that environment. Carr [11] says in those plans in which rights of users are recognized, feelings of alienation can be seen less. In fulfilling the rights of users' sentiment of belonging, sense of allocation increases [12]. In residential areas, since open space is the continuum of the home, reaching residential characteristics has to be the initial aspiration in a landscaping plan.

Designing for quality is also about creating places where people feel comfortable. Good-quality places are clean and well preserved. They are easy to get to and move about in. Qualified spaces can be used for a variety of activities - from energetic sports to simply being somewhere to relax. These spaces attract people to use them and help create a sense of safety and comfort that makes people happy and healthy and encourages them to visit. On the other hand, badly designed and managed spaces can quickly change into neglected eye-sores attracting anti-social behaviour and bringing down the local area. Design quality is essential to how places work. Places that respect their situation and neighbourhood, using it as a starting point to increase local identity, and so connect physically and socially to the surrounding built environment and landscape, are more likely to have a strong and positive identity [13]. An environment should be created to allow residents logical and reasonable opportunities to make changes during their use of space. Too much designing makes it too difficult for users to accept a place with its changing requirements and values. Studies have shown the likelihood of potential changes in space and the ability of space demands to claim, and law suit has so much influence on sense of ownership and attachment to the space. The design and location should be intellectual, creative, and multi-dimensional - not one-dimensional and single-sided. Locations should be flexible in line with the opportunities that may occur [11].

These kind of studies mainly discuss the influence of certain social-spatial factors such as satisfaction with neighbourhood safety, walkability, satisfaction with parks and recreational facilities, the maintenance of streets and other aspects in shared outdoor space, the availability of trees, vehicular circulation, car parking, and the accessibility of common public spaces, the density of traffic in the neighbourhood, the level of noise, the level of crowding, and the length of residence and the 'satisfaction with the neighbourhood as a place to live.' In addition, factors influencing the feel of neighbourhood as home, the level of attachment to place, and the degree of belonging to community are discussed. The subject of environmental evaluation has been addressed from several perspectives and a neighbourhood is both a collection of individuals and a place, the people who live there, and the place itself. Indeed, works on environmental assessment focus either on the place or the person. Works related to design and its quality emphasize evaluation of concrete environmental data. We have categorized our review into six major groups, and further divided these into two overarching categories. The major difference between the two groups is related to centrality of the physical environment in serving the set of needs. Nature's needs are more directly linked with the physical qualities of the environment, while for the human-interaction needs the role of the environment is less significant. As will be seen, the majority of the studies concern several of these categories.

\section{Physical Factors}

\section{Nature and Contact with It}

Previous research in environmental psychology have found that "nature," ranging from wilderness to a view of trees and grass in an urban setting, has at least three systematic, positive effects on people. Each of these effects might also plausibly influence the relationship between greenness and quality of the environment. It has been shown that contact with nature in a variety of forms first reduces mental fatigue [14], secondly relieves feelings of stress and arousal due to stress [15], and thirdly has a positive effect on mood [16]. Researchers have investigated the role of trees on neighbourhood satisfaction. They document the broad range of ways in which contact with nature contributes to higher quality of life and environment, even if the encounter is only a brief opportunity to escape the urban bustle. For example, Farr [17] insisted that harmony with nature is a preferred quality of neighbourhood residents. Hadavi et al. [4] insisted that the most important factors in neighbourhood satisfaction are having access to nearby trees, well-landscaped grounds, and places for walking. Sentiments of nearby nature also influence residential satisfaction in single and multiple family housing clustered together [18]. Kaźmierczak [19] found that spending time in green open common spaces is related to stronger social communication among residents. Several other studies report that natural elements increase public health and reduce levels of violence and crime in the inner-city by aiding in the recovery from mental fatigue [20, 21] . 


\section{Appearance and Aesthetics}

Other factors that influence environment quality and their impacts are not somewhat less than the previous factors, including physical qualities, environmental perceptions, and proximity with signs and local landmarks [22]. Quality of a residential environment depends on features of the environment and their impact on human viewers. The feeling of the environment affects user's feeling by leading them to react to environmental stimuli either in a positive or negative manner. According to Tuan [6], a pleasing landscape must have impact on our senses and provide us with a "shaped" feeling of what we are experiencing. Formal design parameters (e.g., form, variety, unity, order), most common universal indicator of environment quality derived from classical model of human perception, an aesthetic, and also sentimental perception derived from human sensory stimulant in the environment (touch, sound, smell, vision, and taste) and also cognitive constructs (e.g., mystery, safety, and comfort) from an environment are important factors adding pleasure to an aesthetic experience [5]. Attractions of outdoor space for residents can create good opportunities for communication between the individual and the place and between the observers [22]. Community attachment is affected by environmental qualities and perceptual characteristics as well [23]. Hence the elements in the landscape, furniture, and even a single tree that has a particular form constitute identity of place. Space usage is also dependent on its visual beauty and it can reduce or increase the possibility for people to experience the space. The visual quality is often the first stimulus to attract people to places. The visual quality can increase self-esteem among residents and can be a factor in creating a collective identity.

\section{Recreation and Leisure Facilities}

One of the potential benefits of residential complexes is obtaining large areas to create an environment to respond to a wide range of residents' needs in open space and to create an ideal landscape. These needs include a broad extent of activities: walking, jogging, cycling, hiking, and playing sports and games. Children, the elderly, and homemakers are the major users of these spaces, which are appropriate to their particular expectations [24]. Because of their lack of maturity and the need to perform various activities in open spaces for learning life skills, children are more affected by the quality of open space [25]. Suitable designing should provide adequate, specifically designed play areas to accommodate the range of play experiences necessary for children's healthy physical and psychological development. Different factors are considered in designing these spaces: diversity, organization, exploration, fantasy, safe accessibility, attraction, and comfort, providing training, stimulating affections, riskiness, and providing challenge, adventure, and excitement.

\section{Environment Design and Layout}

A physical environment can directly or indirectly help people solve their needs and support humans in their essential needs. Environmental impact on quality of life is related to quality of its physic and its close relationship with human beings in all dimensions of his existence, and that it can be designed according to genuine needs. Coordination and cooperation with people lies in this fact that it makes an environment for them good and pleasant, such that the relationship between people and the environment that meets requirements is a close relationship and attachment. Open spaces, such as other areas of the home environment, are some part of living space and meet the expectations of their residents living there, and they are separated from other spaces with the help of some of the amenities and details that increase design quality, such as entrance quality, type of management, garbage collection system, parking, furniture, names of spaces, and the so forth. These details are seen in a separate section. The design that pays attention to and provides amenities is effective on environmental quality and the satisfaction of residents.

\section{Human Interaction Factors}

\section{Social Interaction}

In residential environments that are open to the participation of residents, outdoor space becomes of a collective nature. This collectiveness does not mean generality; it means a collection of residents who in some type of neighborhood have more things in common in clear and mutual fields and live together. Residential complexes' outdoor spaces extend from inside the house and are part of the life of residents. Residential open space is an essential place for mutual communication and social cognition [26], so this space is full of communications. These spaces are also an environment in which use of space by residents increases because of the inherent potentials of space in a residential area that leads people to expand their sensual communications and be attracted by community. Neighbourhood creates a distinguished character for residents who live in that area and creates identity for them as well. So a neighbourhood can't be considered a simple place - it's a place that meets social and personal daily needs of residents [27]. It should be emphasized that neighbourhood doesn't mean physical closeness as its concept is beyond that and is used in making permanent connections and commonalities between people who live in a definite residential area, and this common area of living leads to visits and permanent connections and to sharing the same concerns about mutual communal spaces.

Some studies have expressed great optimism that social interactions can be improved through a well-designed residential environment [28]. In turn, the 
quality of informal social interaction among neighbours is critical in the quality of environment. According to Finnegan [29], communications between neighbours grow primarily in the course of repeated visual contacts and through short-duration outdoor talks and greetings. Consistent with this, the frequency of faceto-face contacts with neighbours is a strong predictor of both the likelihood that neighbors are friends and the strength of interest between neighbours [30]. There is strong evidence to suggest that social connections do not form solely as a function of the people involved, but also as a function of the context. Crowded, dangerous, and noisy settings all appear to decrease the quality of environment; conditions of crowding and high-density living have been related to poor social relations in a variety of communities [31]; settings in which there is higher degree of crime or high fear of crime are linked to a lack of neighbourhood cohesion [32].

\section{Personal or Individual Factors}

Designers should be careful to preserve the character or uniqueness of place in the face of change [33]. This is a concern for all designers; however, this is specially related to a neighbourhood or residential area with symbolic meaning for all of us. As Randy Hester discovered, changes to the physical and social structure of the town could have a devastatingly disruptive impact on the social and cultural structure of the community. "Social imageability," the collectively held social meanings of a community, is an important part of a neighbourhood's identity [32]. Yi-Fu Tuan [6] believes that people, in an emotional way, have a need to connect to places. There is widespread recognition expressed in several papers that identity is being lost worldwide among citizens in residential neighbourhoods of major urban areas. The reasons behind this loss are attributed to many factors, some of which concern the outdoor design characteristics of these neighbourhoods. In the Middle East some consider identity to be a considerable part of urban and neighbourhood design $[34,35]$. Some Western countries also concentrate on the loss of symbols and place identity of the residential environment [36, 37].

Manzo and Devine-Wright [5] refer to environment as possibilities of that environment where people from the two aspects of cultural and emotional feel are attached and interested in it. They also find space as defined in individual processes or cultural groups. Word of "attachment," which is emphasized and considered by them, refers to feeling and sensual impacts of a place, which is the result of these meanings and processes or the relationships that an individual or a group make with that place or make together considering that place. Moreover, nature [4] and natural landscape [18] help create identity and meaning in common open spaces. In addition, according to Marcus, a house is the atmosphere of childhood and considers it as a place to be socialized, a place for attraction and provocation, and a place for change and industry [38]. Moreover, the creation of capacities for participation of residents in design or change and personalization [39] are qualities that can be effective for giving identity to environment. These qualities provide people with adequate opportunities to develop positive social bonds that imply natural surveillance [22], improvement, and crime prevention [32]. Neal et al. [40] also revealed that the presence of public or semi-public outdoor gatherings improves community identity.

\section{Material and Methods}

\section{Overview of Iran}

In the $1980 \mathrm{~s}$, in conditions affected by revolution, war, and improvement of public health, Iran was faced with a sudden population growth. Boycotts, economic stagnation, social issues after the war, and lack of expert forces in the fields of engineering, architecture, and urban planning policies along with closed governmental policies led to hasty decisions in the field of architecture and urban planning and caused housing to be entangled in a defective and mistake-filled cycle. Some of the most tangible and significant damage is seen in the identity and character of urban housing. Today, public apartments (some units) are dominant in the method of manufacturing in the large cities, and only limited numbers of families with high income afford ownership of single-unit houses.

The effects of changes in modern life in Iran and the subsequent early appearance of modern housing occurred in the 1960s-70s. The history of constructing residential multifamily buildings in Tehran is not so long. In 1963 the first state legislation to encourage private sectors to invest in construction of cheap residential complexes was enacted. Finally, following evolution, the type of modern housing from living in enclosed yards (courtyard living) changed to living in houses with open and public yards, in a way that the main custodians of housing (private sector) with the accompanying support of public sectors regarded the construction of residential complexes as the most suitable way for different classes of people. But since designing principles of the environment and landscaping in planning and designing of open spaces of these complexes are ignored in a way that would be for these spaces (cultural, educational, economic, environmental, ecological, and other factors) and the consequences of theses carelessness are not predicted and essentially regulations and terms of residential environments are applied along with administrative and commercial complexes, so the high density has limited open space and inefficient distribution of the needed functions of the complex has set an improbable and discrete link between open and closed space in today's housing. The result of these views and the main reliance on them and those plans being economical, gradually has led 
to various social, economic, and physical problems for these buildings and their residents.

\section{Study Sites}

Tehran, with a population of around 12,000,000 (according to the 2016 census), is the symbol of history of modern architecture of Iran. The data collection of this research has been accomplished by using four mass housing projects in Tehran, where 235 households were requested to evaluate their existing residential environments by means of a questionnaire comprised of 54 very detailed questions. These complexes are selected among the ones that have designed residential outdoor spaces. As it is said, low-quality outdoor spaces of complexes is visible, so our investigation consists of the ones that have designed residential areas.

\section{Method}

One of the central and key points in the process of research is to select the research method. Which method is used depends on the desired objectives in the study. In the first part of this study, we reviewed previous related studies and expert opinions about shared outdoor space of residential complexes. The aim of this phase is to achieve composite and reliable indices to assess the quality of outdoor spaces of residential complexes using content analysis of qualitative and deep type [41]. The second stage of the present study tries to describe the situation of final indices (Fig. 1) related to the quality of outdoor residential complexes, which is considered descriptive research in methodological terms. The main utilized method in this study to assess the quality factors of open spaces was survey research. Survey research is the description of attitude and behavior of population based on a random and representative sample selected from the population and their response to a series of questions [42]. According to Baker [42], this research should be referred to as descriptive research. For the implementation of investigations, a questionnaire consisting of related questions to the indices was prepared to evaluate the quality of open space complex based on views of residential complexes residents. So the final analysis units in this study are residential complexes.

Among different residential complexes, by purposeful sampling method, four complexes (Fajr, Mahan, Zeytoun, Chahar Sad Dastgah) have been selected for reference and data collection, because first,
Sense of security during outdoor activities Feeling disturbance from others outdoor activities Sense of ownership Sense of belonging Rights of residents Being a meaningful environment Attachment to part or all of outdoor environment Personalization opportunities Desirable sense of density Offering privacy to residents Personal or individual factors

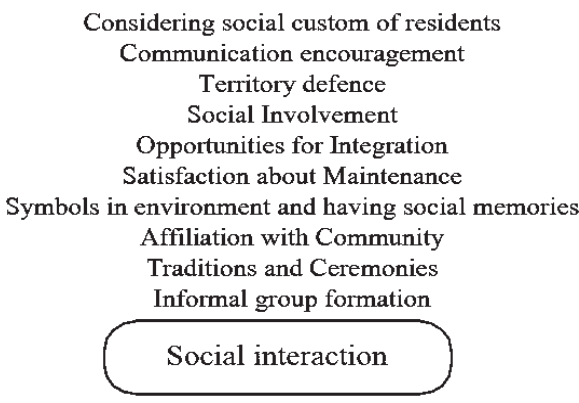

onsidering social custom of residents unication encouragement Territory defence Social Involvemen pportunities for Integration atisfaction about Maintenance Affiliation with Community Traditions and Ceremonies ormal group formation Social interaction

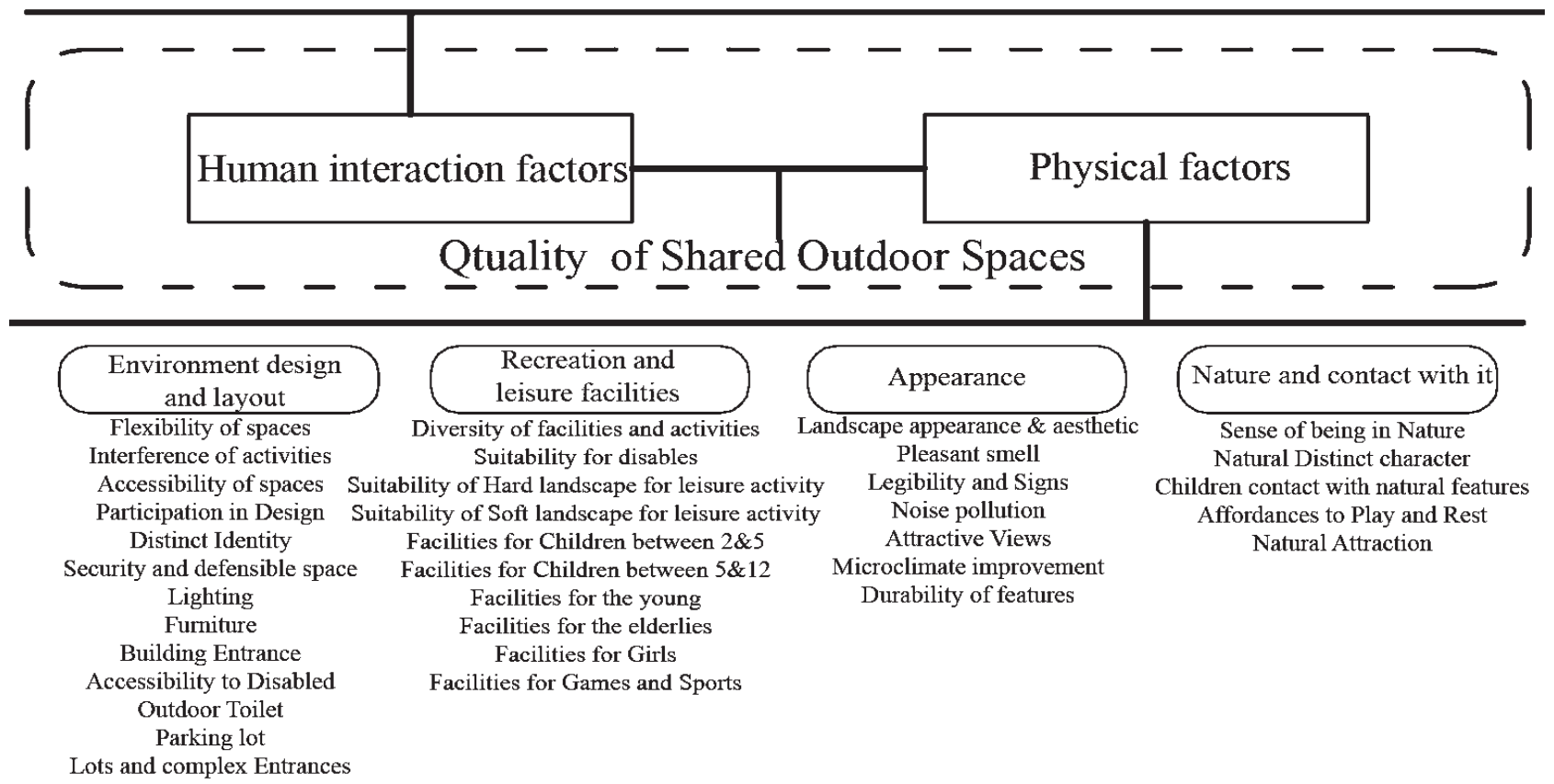

Fig. 1. Quality of outdoor residential complex indices. 
Table 1. Chronbach's Alpha.

\begin{tabular}{|c|c|c|c|c|}
\hline \multicolumn{5}{|c|}{ Nature and contact with it (Total Alpha: 0.649) } \\
\hline & $\begin{array}{c}\text { Scale Mean if Item } \\
\text { Deleted }\end{array}$ & $\begin{array}{l}\text { Scale Variance } \\
\text { if Item Deleted }\end{array}$ & $\begin{array}{c}\text { Corrected Item-Total } \\
\text { Correlation }\end{array}$ & $\begin{array}{l}\text { Cronbach's Alpha } \\
\text { if Item Deleted }\end{array}$ \\
\hline Sense of being in Nature & 13.29 & 7.109 & .443 & .580 \\
\hline Natural Distinct character & 13.54 & 6.304 & .505 & .543 \\
\hline Children contact with natural features & 13.94 & 6.763 & .463 & .568 \\
\hline Affordances to Play and Rest & 14.24 & 7.944 & .222 & .674 \\
\hline Natural Attraction & 13.50 & 6.686 & .394 & .602 \\
\hline \multicolumn{5}{|c|}{ Appearance and Aesthetic (Total Alpha: 0.369) } \\
\hline Pleasant smell & 19.98 & 9.297 & .329 & .236 \\
\hline Legibility and Signs & 20.58 & 8.944 & .291 & .247 \\
\hline Noise pollution & 20.08 & 12.674 & -.169 & .508 \\
\hline Attractive Views & 20.30 & 9.710 & .222 & .297 \\
\hline Microclimate improvement & 20.27 & 9.403 & .378 & .220 \\
\hline Durability of features & 20.13 & 12.094 & -.091 & .465 \\
\hline \multicolumn{5}{|c|}{ Environment design and layout (Total Alpha: 0.758) } \\
\hline Flexibility of spaces & 38.57 & 47.091 & .498 & .731 \\
\hline Interference of activities & 39.28 & 46.120 & .413 & .739 \\
\hline Accessibility of spaces & 38.60 & 46.112 & .553 & .724 \\
\hline Participation in Design & 39.49 & 46.157 & .486 & .730 \\
\hline Distinct Identity & 39.64 & 48.319 & .343 & .747 \\
\hline Security and defensible space & 39.17 & 48.630 & .390 & .742 \\
\hline Lighting & 38.62 & 49.078 & .314 & .750 \\
\hline Furniture & 38.73 & 48.743 & .351 & .746 \\
\hline Building Entrance & 38.59 & 48.527 & .364 & .744 \\
\hline Accessibility to Disabled & 39.09 & 47.987 & .455 & .735 \\
\hline Outdoor Toilet & 39.60 & 49.126 & .341 & .747 \\
\hline Parking lot & 38.16 & 53.275 & .080 & .770 \\
\hline Lots and complex Entrances & 39.03 & 47.710 & .367 & .744 \\
\hline \multicolumn{5}{|c|}{ Recreation and leisure facilities (Total Alpha: 0.818) } \\
\hline Diversity of facilities and activities & 26.00 & 46.758 & .271 & .823 \\
\hline Suitability for disables & 25.83 & 46.900 & .271 & .823 \\
\hline $\begin{array}{l}\text { Suitability of Hard landscape for } \\
\text { leisure activity }\end{array}$ & 26.23 & 45.710 & .324 & .819 \\
\hline $\begin{array}{c}\text { Suitability of Soft landscape for } \\
\text { leisure activity }\end{array}$ & 26.43 & 44.314 & .386 & .814 \\
\hline Facilities for Children between $2 \& 5$ & 26.54 & 41.311 & .597 & .791 \\
\hline Facilities for Children between $5 \& 12$ & 26.56 & 40.394 & .739 & .777 \\
\hline Facilities for the young & 26.65 & 39.330 & .723 & .776 \\
\hline Facilities for the elderlies & 26.42 & 37.646 & .734 & .772 \\
\hline Facilities for Girls & 27.06 & 41.130 & .606 & .790 \\
\hline Facilities for Games and Sports & 26.43 & 44.721 & .346 & .818 \\
\hline
\end{tabular}


Table 1. Continued.

\begin{tabular}{|c|c|c|c|c|}
\hline \multicolumn{5}{|c|}{ Nature and contact with it (Total Alpha: 0.649) } \\
\hline & $\begin{array}{c}\text { Scale Mean if Item } \\
\text { Deleted }\end{array}$ & $\begin{array}{l}\text { Scale Variance } \\
\text { if Item Deleted }\end{array}$ & $\begin{array}{c}\text { Corrected Item-Total } \\
\text { Correlation }\end{array}$ & $\begin{array}{l}\text { Cronbach's Alpha } \\
\text { if Item Deleted }\end{array}$ \\
\hline Sense of being in Nature & 13.29 & 7.109 & .443 & .580 \\
\hline Natural Distinct character & 13.54 & 6.304 & .505 & .543 \\
\hline Children contact with natural features & 13.94 & 6.763 & .463 & .568 \\
\hline Affordances to Play and Rest & 14.24 & 7.944 & .222 & .674 \\
\hline \multicolumn{5}{|c|}{ Social interaction (Total Alpha: 0.671 ) } \\
\hline Considering social customs & 29.78 & 24.912 & .450 & .626 \\
\hline Communication encouragement & 29.57 & 34.147 & -.374 & .767 \\
\hline Territory defense & 29.71 & 24.904 & .449 & .626 \\
\hline Social Involvement & 29.57 & 24.505 & .488 & .619 \\
\hline Opportunities for Integration & 29.70 & 25.506 & .328 & .648 \\
\hline Satisfaction about Maintenance & 29.81 & 26.428 & .318 & .650 \\
\hline $\begin{array}{l}\text { Symbols in environment and having } \\
\text { social memories }\end{array}$ & 29.70 & 23.182 & .569 & .599 \\
\hline Affiliation with Community & 29.91 & 25.205 & .466 & .625 \\
\hline Traditions and Ceremonies & 30.06 & 24.475 & .363 & .641 \\
\hline Informal group formation & 30.18 & 23.018 & .442 & .623 \\
\hline \multicolumn{5}{|c|}{ Personal or Individual factors (Total Alpha: 0.832 ) } \\
\hline $\begin{array}{c}\text { Sense of security during outdoor } \\
\text { activities }\end{array}$ & 27.02 & 50.710 & .153 & .841 \\
\hline $\begin{array}{c}\text { Feeling disturbance from others } \\
\text { outdoor activities }\end{array}$ & 26.43 & 43.851 & .458 & .823 \\
\hline Sense of ownership & 25.91 & 42.645 & .526 & .816 \\
\hline Sense of belonging & 26.19 & 41.480 & .606 & .808 \\
\hline Rights of residents reorganization & 25.58 & 42.330 & .653 & .805 \\
\hline Being a meaningful environment & 25.44 & 41.219 & .613 & .807 \\
\hline $\begin{array}{c}\text { Attachment to part or all of outdoor } \\
\text { environment }\end{array}$ & 26.02 & 39.612 & .672 & .800 \\
\hline Personalization opportunities & 26.24 & 41.956 & .569 & .812 \\
\hline Desirable sense of density & 26.27 & 43.349 & .476 & .821 \\
\hline Offering privacy to residents & 27.10 & 44.130 & .415 & .828 \\
\hline
\end{tabular}

in terms of location, the spatial dispersion condition is met and complexes are representative of different areas of Tehran; second, most of their residents are middle-class people who make up most of the population of Iran; and third, with this decision, it is possible to survey and compare three types of complexes in terms of height (high-rise, medium-rise, and low-rise) and in analytical terms, this is an advantage for this research.

Statistical methods employed for the analysis of questionnaire data obtained in this study consist of one-variable indices. One-variable descriptive indices used here include mean and relative distributions. The ultimate criterion for assessing the credit quality of residential open space is Cronbach's alpha statistical test. Cronbach's alpha test is used to review internal correlation of the index components, and if necessary, to reduce or add a component to the index. Tavakol in a paper has dealt with clarification of the application and interpretation of this coefficient in various research, such as medical research, and explains that calculating alpha has become common practice in medical education research when multiple-item measures of a concept or construct are employed. This is because it is 
Table 2. Frequency.

\begin{tabular}{|c|c|c|c|c|c|}
\hline \multicolumn{6}{|c|}{ Nature and contact with it } \\
\hline & & Frequency & Percent & Valid Percent & Cumulative Percent \\
\hline \multirow{4}{*}{ Valid } & Low & 188 & 80.0 & 80.0 & 80.0 \\
\hline & Moderate & 42 & 17.9 & 17.9 & 97.9 \\
\hline & High & 5 & 2.1 & 2.1 & 100.0 \\
\hline & Total & 235 & 100.0 & 100.0 & \\
\hline \multicolumn{6}{|c|}{ Appearance and aesthetic } \\
\hline \multirow{4}{*}{ Valid } & Low & 205 & 87.2 & 87.2 & 87.2 \\
\hline & Moderate & 29 & 12.3 & 12.3 & 99.6 \\
\hline & High & 1 & .4 & .4 & 100.0 \\
\hline & Total & 235 & 100.0 & 100.0 & \\
\hline \multicolumn{6}{|c|}{ Recreation and leisure facilities } \\
\hline & Low & 209 & 88.9 & 89.7 & 89.7 \\
\hline & Moderate & 22 & 9.4 & 9.4 & 99.1 \\
\hline & High & 2 & .9 & .9 & 100.0 \\
\hline & Total & 233 & 99.1 & 100.0 & \\
\hline \multicolumn{2}{|r|}{ Missing System } & 2 & .9 & & \\
\hline \multicolumn{2}{|r|}{ Total } & 235 & 100.0 & & \\
\hline \multicolumn{6}{|c|}{ Social interaction } \\
\hline \multirow{4}{*}{ Valid } & Low & 216 & 91.9 & 91.9 & 91.9 \\
\hline & Moderate & 18 & 7.7 & 7.7 & 99.6 \\
\hline & High & 1 & .4 & .4 & 100.0 \\
\hline & Total & 235 & 100.0 & 100.0 & \\
\hline \multicolumn{6}{|c|}{ Personal or Individual factors } \\
\hline \multirow{4}{*}{ Valid } & Low & 209 & 88.9 & 88.9 & 88.9 \\
\hline & Moderate & 24 & 10.2 & 10.2 & 99.1 \\
\hline & High & 2 & .9 & .9 & 100.0 \\
\hline & Total & 235 & 100.0 & 100.0 & \\
\hline \multicolumn{6}{|c|}{ Environment design and layout } \\
\hline \multirow{4}{*}{ Valid } & Low & 212 & 90.2 & 90.2 & 90.2 \\
\hline & Moderate & 22 & 9.4 & 9.4 & 99.6 \\
\hline & High & 1 & .4 & .4 & 100.0 \\
\hline & Total & 235 & 100.0 & 100.0 & \\
\hline \multicolumn{6}{|c|}{ Total Quality Index } \\
\hline \multirow{3}{*}{ Valid } & Low & 221 & 94.0 & 94.4 & 94.4 \\
\hline & Moderate & 13 & 5.5 & 5.6 & 100.0 \\
\hline & Total & 234 & 99.6 & 100.0 & \\
\hline \multicolumn{2}{|r|}{ Missing System } & 1 & .4 & & \\
\hline \multicolumn{2}{|r|}{ Total } & 235 & 100.0 & & \\
\hline
\end{tabular}


Fig. 3. Comparison of low-, medium-, and high-rise residential complexes.

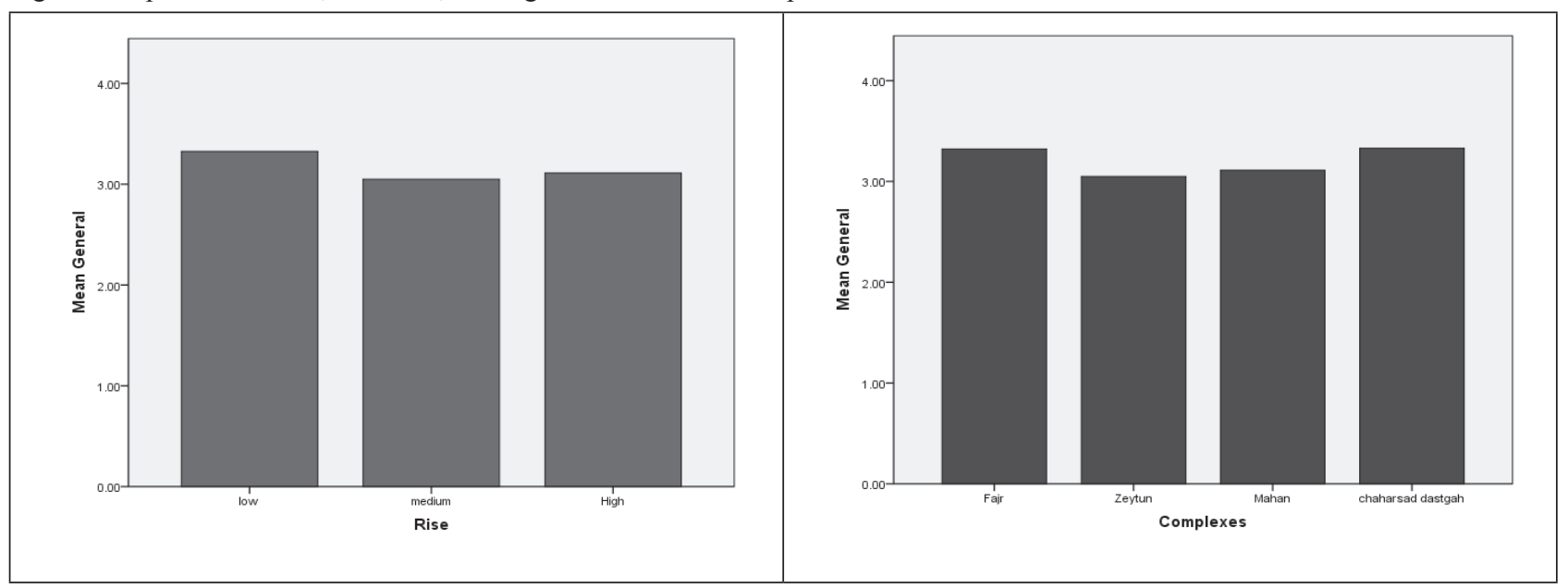

easier to use in comparison to other estimates (e.g., test retest reliability estimates) as it only requires one test administration [43].

\section{Results and Discussion}

\section{Validity of the Survey}

Cronbach's alpha coefficient was calculated to check for internal consistency of each component index. According to Table 1, in all 6 indicators (except indices of aesthetic and appearance), which were considered as representative of each index, with the other components of the index, have high internal correlation. Components of nature index, with regard to Alpha coefficient, have 0.64 internal correlations, which is relatively high. This coefficient for the leisure and entertainment index is 0.81 and represents a very high correlation between the reagents of this index. Cronbach's alpha coefficient for the association index represents the number 0.67 , which shows the strong correlation among its components. Internal correlation of components of identity and perception index, based on the alpha coefficient, is 0.75 , which is a high correlation. This coefficient with number 0.83 shows very high internal correlation between the constituent elements of rest index. In addition to these five indices, Cronbach's alpha coefficient for aesthetic and appearance index shows 0.36, which represents not high correlation between components of this index. It seems that a strong correlation is related to deviation of answers, since the table shows that by removing any of the components of the index, a significant change in this ratio does not occur.

\section{Frequency Table}

A frequency table provides the opportunity to review the amount and distribution of respondents' opinions about the design quality of outdoor space. As in Table 2, respondents' assessments about every
6 indicators relating to the quality of shared outdoor space represents poor quality of their shared outdoor space in their view, so that 80 percent of respondents have pointed to the low quality of reagents of nature. The table related to aesthetic index also shows that 87 percent of the residents assessed the quality of these indicators as low. For recreation and leisure amenities, those who believe in poor quality of their residential complexes include 88 percent of respondents. This level for perception and identity index is nearly 89 percent, and for the index of facilities is 92 percent. Also, respondents in more than 90 percent of cases agreed with the low-quality of index of social interaction, which as with other indicators, confirms the belief that residents believe in the low quality of shared outdoor space.

\section{General Quality Index}

As the conclusion of the table of six indicators shows, we can also check the overall quality of shared outdoor space visible in the last part of Table 2 and confirm the lowness of quality of shared outdoor spaces. In this way, none of the respondents believe in the high quality of shared outdoor space. Also, $5.5 \%$ of residents have provided an average assessment of these indicators, while $94 \%$ of total respondents assess this index about their residential complexes as low and believe in the low quality of shared outdoor space. The fact that $94 \%$ of respondents assessed this low index confirms this hypothesis of lowness of quality of shared outdoor spaces on which this research has focused.

\section{Comparison between Low, Medium,} and High-rise Residential Complexes

Information obtained from questionnaires allows for comparisons between four complexes and also between three types of complexes (low-rise, medium-rise, and high-rise). This can be done using the following 
graphs (Fig. 3), which show that there is no significant difference between residents of different complexes in this study. In an analysis of the index of quality of shared open space similar results are obtained. Also, by dividing complexes into three types of high-rise, medium-rise, and high-rise residents, it seems that assessing the quality of shared open spaces by residents in different types of complexes is almost identical.

\section{Conclusion}

Complexes that show no escape from them in modern life are some kind of house-building nowadays. The reason behind sharing some facilities such as outdoor space in these buildings is to reduce finished costs. In this change process, the residential areas, from houses with separate yards has converted into houses with a common outdoor space, which has made many changes on housing. But the human need to live up in house has been unchanged from the past. So people have unconscious expectations about residential environments and will find life in peace and in contact with nature and sky. People know life depends on the residence and that the residence depends on life. Hence a home has some meaning of life.

Designers have limited powers and abilities in residential landscape design. They can never change the type of realm. But they can identify the basic needs of residents, i.e., practical needs of residents, including playgrounds for children, adult rest areas, etc. They can create an environment which, in addition to meet fundamental needs of residents, does not cause Contradiction and conflict in the relations between them.

In developing countries that often have imitated this approach to modern manifestations, lack of knowledge is visible in many of these imitations. Lack of attention to open spaces as a main part of living space and lack of plans and clear rules are the major problems of residential construction in Iran. As a natural result of low-quality planning and design in residential areas, residents' dissatisfaction with the quality of the outdoor environment is visible, and this study has explicitly come to this conclusion. So in near future, with improvement of knowledge and modification of rules, destruction or fundamental changes in most of these complexes is predictable, which will have high costs for them today because of poor quality of spaces and lack of attention to resident needs and, in the future, because of changes and modification.

\section{Acknowledgements}

We are thankful to Dr. Hamid Nadimi and Mehrdad Qayyommi for their recommendations.

\section{Conflict of Interest}

The authors declare no conflict of interest.

\section{References}

1. CURL A., THOMPSON C.W., ALVES S., ASPINALL P. Outdoor Environmental Supportiveness and Older People's Quality of Life: A Personal Projects Approach. Journal of Housing for the Elderly. 30, 1, 2016.

2. KNIES G., NANDI A., PLATT L. Life satisfaction, ethnicity and neighbourhoods: Is there an effect of neighbourhood ethnic composition on life satisfaction? Social science research. 60, 110, 2016.

3. HUANG Z., DU X. Assessment and determinants of residential satisfaction with public housing in Hangzhou, China. Habitat International. 47, 218, 2015.

4. HADAVI S., KAPLAN R., HUNTER M.C.R. Environmental affordances: A practical approach for design of nearby outdoor settings in urban residential areas. Landscape and Urban Planning. 134, 19, 2015.

5. MANZO L.C., DEVINE-WRIGHT P. Place attachment: Advances in theory, methods and applications. Routledge, 2013.

6. TUAN Y.-F. Topophilia: A study of environmental perceptions, attitudes, and values. Columbia University Press, 2013.

7. VAN HERZELE A., DE VRIES S. Linking green space to health: A comparative study of two urban neighbourhoods in Ghent, Belgium. Population and Environment. 34, 171, 2012.

8. BUONFINO A., HILDER P. Neighbouring in Contemporary Britain. A Thinkpiece for the Joseph Rowntree Foundation Housing and Neighbourhoods Committee. York: Joseph Rowntree Foundation. 2006.

9. BUYS L., MILLER E. Residential satisfaction in inner urban higher-density Brisbane, Australia: role of dwelling design, neighbourhood and neighbours. Journal of Environmental Planning and Management. 55, 319, 2012.

10. OKTAY D., RUSTEMLI A., MARANS R.W. Neighborhood satisfaction, sense of community, and attachment: Initial findings from Famagusta quality of urban life study. ITU A/Z Journal. 6, 6, 2009.

11. CARR S. Public space. Cambridge University Press, 1992.

12. HUMMON D.M. Commonplaces: Community ideology and identity in American culture. SUNY Press, 1990.

13. LOVETT M.G., CHI Y.N. Place attachment among college students related to community engagement through service-learning. International Journal of Education Research. 10, 2015.

14. BERTO R. The role of nature in coping with psychophysiological stress: a literature review on restorativeness. Behavioral sciences. 4, 394, 2014.

15. BRATMAN G.N., HAMILTON J.P., DAILY G.C. The impacts of nature experience on human cognitive function and mental health. Annals of the New York Academy of Sciences. 1249, 118, 2012.

16. THOMPSON COON J., BODDY K., STEIN K., WHEAR R., BARTON J., DEPLEDGE M.H. Does participating in physical activity in outdoor natural environments have a greater effect on physical and mental wellbeing 
than physical activity indoors? A systematic review. Environmental science \& technology. 45, 1761, 2011.

17. FARR D. Sustainable urbanism: Urban design with nature. John Wiley \& Sons, 2011.

18. LI Z., WU F. Residential satisfaction in China's informal settlements: A case study of Beijing, Shanghai, and Guangzhou. Urban Geography. 34, 923, 2013.

19. KAŹMIERCZAK A. The contribution of local parks to neighbourhood social ties. Landscape and Urban Planning. 109, 31, 2013.

20. KAPLAN R., KAPLAN S. The experience of nature: A psychological perspective. CUP Archive, 1989.

21. ULRICH R.S. Natural versus urban scenes some psychophysiological effects. Environment and Behavior. 13, 523, 1981.

22. RAPOPORT A. Human aspects of urban form: towards a man-environment approach to urban form and design. Elsevier, 2016.

23. ANTON CE, LAWRENCE C. Home is where the heart is: The effect of place of residence on place attachment and community participation. Journal of Environmental Psychology. 40, 451, 2014.

24. KARUPPANNAN S., SIVAM A. Comparative analysis of utilisation of open space at neighbourhood level in three Asian cities: singapore, delhi and kuala lumpur. Urban Design International. 18, 145, 2013.

25. MARCUS C.C., SARKISSIAN W. Housing as if people mattered: Site design guidelines for medium-density family housing. Univ of California Pr, 1988.

26. PETERS K., ELANDS B., BUIJS A. Social interactions in urban parks: Stimulating social cohesion? Urban forestry \& urban greening. 9, 93, 2010.

27. ERGAS C. A model of sustainable living: Collective identity in an urban ecovillage. Organization \& Environment. 23, 32, 2010.

28. GEHL J. Life between buildings: using public space. Island Press, 2011.

29. FINNEGAN R. Communicating: The multiple modes of human communication. Routledge, 2014

30. SHARMEEN F., ARENTZE T., TIMMERMANS H. Dynamics of face-to-face social interaction frequency: role of accessibility, urbanization, changes in geographical distance and path dependence. Journal of Transport Geography. 34, 211, 2014.

31. RAMAN S. Designing a liveable compact city: Physical forms of city and social life in urban neighbourhoods. Built Environment. 36, 63, 2010.

32. SCARBOROUGH B.K., LIKE-HAISLIP T.Z., NOVAK K.J., LUCAS W.L., ALARID L.F. Assessing the relationship between individual characteristics, neighborhood context, and fear of crime. Journal of Criminal Justice. 38, 819, 2010.

33. SOUTHWORTH M., RUGGERI D. Place, Identity And The Global City. Urban Design Companion London: Routledge. 2010.

34. CHIODELLI F. Planning illegality: The roots of unauthorised housing in Arab East Jerusalem. Cities. 29, 99, 2012.

35. KALLUS R., KOLODNEY Z. Politics of urban space in an ethno-nationally contested city: negotiating (co) existence in Wadi Nisnas. Journal of Urban Design. 15, 403, 2010.

36. LEWICKA M. Place attachment: How far have we come in the last 40 years? Journal of Environmental Psychology. 31, 207, 2011.

37. BRUGGER A., KAISER F.G., ROCZEN N. One for All? European Psychologist. 2011.

38. MARCUS C.C., FRANCIS C. Growing up in a danger zone: How modernization efforts can improve the environment of childhood in public housing. Children's Environments. 57, 1995.

39. CARMONA M. Public places, urban spaces: the dimensions of urban design. Routledge, 2010.

40. NEAL S., BENNETT K., JONES H., COCHRANE A., MOHAN G. Multiculture and Public Parks: Researching Super-diversity and Attachment in Public Green Space. Population, space and place. 21, 463, 2015.

41. HSIEH H.-F., SHANNON S.E. Three approaches to qualitative content analysis. Qualitative health research. 15, 1277, 2005.

42. BAKER T.L., RISLEY A.J. Doing social research. 1994.

43. TAVAKOL M., DENNICK R. Making sense of Cronbach's alpha. International journal of medical education. 2, 53, 2011. 
